\title{
Making the most of the federal investment of $\$ 5$ billion for mental health
}

\author{
Mary Bartram MSc RSW
}

— Cite as: CMAJ 2017 November 6;189:E1360-3. doi: 10.1503/cmaj.170738

$\mathbf{T}$ he 2017/18 Canadian federal budget confirmed that $\$ 5$ billion will be transferred to provincial and territorial governments over the next 10 years to improve access to mental health services. ${ }^{1}$ This $\$ 500$ million per year (on average) is a historic first step but falls short of closing the estimated \$3.1-billion annual gap in funding. ${ }^{2}$ Vigilance and a spirit of learning will be required to make sure that the new investment goes as far as possible to reducing unmet needs for and inequities in access to mental health services. At the same time, efforts must continue to reallocate current funding toward broader transformation of the mental health system. ${ }^{3}$

\section{Why is there a need for targeted federal funding for mental health services in Canada?}

Mental health services have been chronically neglected as health policy in Canada has evolved. ${ }^{2}$ In 1957, whether or not to include mental health facilities in the Hospital Insurance and Diagnostic Services Act was the subject of fierce debate. The federal government argued that mental hospitals were already being funded by provincial governments and should not be included. Although the hospital insurance law passed, this position was criticized as discriminatory evasion of a costly responsibility on dubious jurisdictional grounds. Mental illness has continued to be too stigmatized, too jurisdictionally thorny and deemed too expensive - given its high prevalence - to be considered enough of a priority to justify the use of federal spending power. For example, the 1984 Canada Health Act did not require provincial health insurance to broaden coverage beyond physicians and hospitals, innovation under the transition funds in the 1990s was limited to a small number of mental health-related pilots, and only "short-term acute mental health homecare" was included in the health reform priorities for the 2004 Health Accord. ${ }^{4}$ In the absence of targeted federal support, provincial and territorial governments have been hard pressed to narrow the gap in funding for mental health services. With spending on mental health at only $7 \%$ of public spending on health, Canada trails behind other Organisation for Economic Co-operation and Development countries, some of which spend as much as $18 \%$; England channels $13 \%$ of total health spending to mental health. ${ }^{5,6}$

The underfunding and narrow public insurance coverage of mental health services in Canada have contributed to high rates of

\section{KEY POINTS}

- Chronic underfunding and long-standing gaps in insurance coverage have resulted in high rates of unmet need and inequities in access to mental health services.

- A new investment of $\$ 500$ million per year to improve access to mental health services is welcome but falls short of closing the estimated \$3.1-billion annual gap in funding.

- Mental health reforms in the United Kingdom and Australia have improved access to some services, but equitable distribution of gains remains elusive.

- Making the most of the new federal mental health transfer will require strong accountability frameworks, a spirit of learning across jurisdictions and a focused research agenda, as well as public transparency regarding bilateral transfer agreements.

unmet need for care and inequities in access. Evidence regarding the scope of the problem is summarized in Table 1. Analysis of data from the 2012 Canadian Community Health Survey-Mental Health has shown that one in three Canadians over 14 years of age who reported having a need for counselling also reported that this need was either unmet or only partially met, ${ }^{7}$ and income and education were significant predictors of utilization of mental health services. ${ }^{9}$ Estimates from the insurance industry suggest that 12 million Canadians face additional financial barriers to accessing services that are not covered by their provincial or territorial insurance plans, because they do not have employment-based benefits. ${ }^{8}$ Recent data from the Canadian Institute for Health Information showed increases in admissions to hospital and visits to emergency departments for mental health conditions among children and youth even though the prevalence of mental illness has not changed; such increased demand for services will only exacerbate inequities in access. ${ }^{10}$ Having adequate mental health services is only one element in a range of services and supports needed to prevent mental illness, treat it and foster recovery of a meaningful life in community, but it is an important one. ${ }^{11}$

Gaps in mental health services have had a substantial impact on productivity in the workplace and, by extension, on government revenues and economic growth. A recent report from the Conference Board of Canada estimated that the Canadian economy could gain up to $\$ 49.6$ billion annually if all employed Canadians with depression and anxiety received optimal treatment. ${ }^{12}$ 


\section{Will the federal $\$ 5$ billion be enough?}

In 2012, the Mental Health Strategy for Canada recommended a target of $9 \%$ of overall health spending for mental health. ${ }^{3}$ A recent analysis based on Canadian Institute for Health Information data from 2015 conservatively estimated that public funding in the form of government transfers would need to increase to $\$ 3.1$ billion per year, with an incremental base funding increase of $\$ 310$ million each year, to achieve the target. ${ }^{2}$ In addition, to close the gap fully, provincial and territorial governments would need to come up with an additional $\$ 2.6$ billion over and above the new federal transfer of $\$ 500$ million per year. ${ }^{2}$ Given the important role of social spending in supporting mental health, the Mental Health Strategy for Canada also called for a two percentage point increase in mental health's share of social spending, which, if added to the estimate, would further increase what is required to support effective mental health policy in Canada. ${ }^{3}$

\section{What can we learn from others about wise investments in mental health services?}

Over the past decade, both the United Kingdom and Australia have made major investments in improving access to mental health services, particularly psychological therapies (Table 2). The Better Access to Psychiatrists, Psychologists and General Practitioners through the MBS (Medicare Benefits Schedule) initiative ("Better Access") was launched in response to 1997 Australian survey data that showed high rates of unmet need, with only $38 \%$ of people with mood, anxiety or substance use disorders using services. ${ }^{18}$ The Australian government, which already had jurisdiction over public health insurance for primary care (Medicare), simply added psychologists and other mental health professionals as eligible providers and let the professional associations regulate the quality of care. Since Better Access was introduced, analysis of administrative and epidemiologic data has shown that patients (with referral from their physicians) have taken advantage of the broader array of publicly funded services: treatment rates rose to $46 \%$ of people with mental disorders in 2009/10. ${ }^{13}$ In contrast, the key motivation behind the introduction of Improving Access to Psychological Therapies program in England in 2008 was the potential return on investment from improving productivity in the workforce. ${ }^{19}$ With tight standards and hard targets set by the UK government and implemented by the National Health Service in England, this program is mainly focused on providing cognitive behavioural therapy to people with common mental health problems (i.e., depression and anxiety). As of January 2017, data gathered by providers of the program showed that $50 \%$ of patients with severe enough symptoms of depression and anxiety to be considered a clinical case at the outset of treatment no longer met these criteria, thus meeting the $50 \%$ target for clinical recovery set by the UK government. ${ }^{15}$

Despite their successes at the population level, both the insurance-based Better Access model and the programmatic Improving Access to Psychological Therapies model have faced challenges in

Table 1: Gaps in mental health care in Canada

\section{Problem}

Unmet need

Insurance gap

Funding gap

\section{Evidence}

One in three Canadians who report a need for counselling say the need is unmet or only partially met. ${ }^{7}$

Twelve million Canadians do not have insurance for health services not covered by provincial or territorial plans. ${ }^{8}$

3.1 billion dollars are needed annually to increase mental health share from $7 \%$ to $9 \%$ of public spending on health; federal transfer of $\$ 500$ million per year on average. ${ }^{2}$

\section{Table 2: International options for improving access to psychotherapy services}

\section{Solution}

From Australia: Better Access to Psychiatrists, Psychologists and General Practitioners through the MBS (Better Access) initiative (2006)

From UK (England): Improving Access to Psychological Therapies program (2008)

A cost-benefit analysis from Canada

\section{Evidence}

Utilization increased: Treatment rates for people with anxiety, depression and substance use disorders rose from $38 \%$ to $46 \%$ by 2009/10. ${ }^{13}$

Inequitable uptake: 68 psychologist consultations per 1000 residents were billed to the Better Access program in the most advantaged areas versus 23 per 1000 in the least advantaged areas. ${ }^{14}$

Strong overall outcomes: $50 \%$ target for clinical recovery met by 2017..$^{15}$

Inequitable outcomes: $35 \%$ recovery rate in most deprived decile versus $55 \%$ in the least deprived decile. ${ }^{16}$

Estimated $\$ 2$ in savings to society received for every $\$ 1$ invested in expanding Medicare coverage of psychological services. ${ }^{17}$ 
providing equitable improvements in access to care. Data (2015/16) from the National Health Service in England showing that recovery rates in the most deprived decile were only $35 \%$, compared with $55 \%$ in the least deprived decile, have prompted the Improving Access to Psychological Therapies program to work toward improving the quality of services in more deprived areas. ${ }^{16}$ Similarly, 68 psychologist consultations were billed to Better Access for each 1000 residents in the most socioeconomically advantaged areas in Australia compared with 23 per 1000 in the least advantaged areas. ${ }^{14}$ In response, the Australian government recently expanded coverage of telemental health under the program, and new Primary Health Networks are intended to be more responsive to local needs. ${ }^{20,21}$ The Better Access program also had higher than projected costs, with spending increasing an average of $8.5 \%$ per year between 2007 and $2011 .{ }^{22}$

\section{What will it take to ensure a good return on the federal government's investment?}

Given the lessons from Canadian history and from the reforms in the UK and Australia, it will take vigilance and a spirit of learning in Canada to make the most of the recently announced $\$ 5$ billion federal transfer. The government's 2017 federal budget may represent a historic advance for mental health policy in Canada, yet it was widely labelled as a disappointing budget. ${ }^{23}$ Mental health is still not recognized as a top priority in Canada, and there is a real risk that policy gains may be derailed yet again by jurisdictional dynamics, stigma and fiscal pressures.

\section{Clear accountability frameworks}

Vigilance from all levels of government, the stakeholder community and the voting public will be required to ensure that rigorous accountability frameworks for each of the bilateral transfer agreements are developed. Moreover, accountability frameworks for the new federal investments have the potential to leverage much-needed improvements in performance measurement for the mental health system as a whole, where most spending will continue to happen. Ideally, a national framework could be agreed upon that would allow for comparability across the country, building on the six preliminary performance indicators identified by the Centre for Applied Research in Mental Health and Addiction. ${ }^{24}$

Stand-alone provincial and territorial frameworks could also be effective if they are implemented systematically and reported on publicly. These frameworks need to include mechanisms to ensure that new investments are spent on new mental health services (rather than on other priorities), and services are based on best available evidence. New standards for the treatment of major depression from Health Quality Ontario (and other provincial or clinical standards) could contribute to such a mechanism, ${ }^{25}$ as could the recent synthesis of the return on investment of best practices - from suicide prevention to psychological therapies to Housing First - by the Mental Health Commission of Canada. ${ }^{26}$

Both improving access and outcomes at the population level and ensuring that these improved outcomes are equitably dis- tributed should be clear objectives from the outset, with data collected to monitor progress. Performance monitoring could be modelled after the rigorous approach used by the Improving Access to Psychological Therapies program, with clinical data collected at each session and reported monthly by overall progress as well as by demographic factors such as district, ethnic group and level of disadvantage. ${ }^{16}$

\section{Spirit of learning}

With clear accountability frameworks in place and closely watched, the stage will be set for a spirit of learning. Here, Canada can take advantage of the benefits of its decentralized system. Ideally, jurisdictions will have flexibility under each bilateral agreement to implement a range of approaches, with different mixes of universal, targeted, insurance-based and programmatic elements. ${ }^{27}$ For example, Ontario has announced that it will (at a minimum) introduce a new structured psychotherapy program, enhance integrated services for youth and provide more supportive housing:28 another jurisdiction could elect to cover psychotherapy for children and youth without access to employmentbased insurance. Learning across jurisdictions can be fostered by marshalling the resources of pan-Canadian health organizations. In addition to the example provided by the return-on-investment report from the Mental Health Commission of Canada, ${ }^{26}$ the Canadian Institute for Health Information will be releasing new data in 2018 on the workforce involving psychologists and social workers, ${ }^{29}$ and the Canadian Foundation for Healthcare Improvement could scale up best practices in mental health along the lines of their work on reducing antipsychotic overprescribing in long-term care facilities. ${ }^{30}$

\section{Focused research agenda}

The Canadian Institutes of Health Research (CIHR) could work with the health services and policy research community to develop a focused research agenda and put out a special priority-driven call on the impact of the targeted federal transfers for mental health and home care. It will be important to track how much provincial and territorial governments actually spend on mental health services over the next 10 years and what they spend it on. Tracking changes in unmet need, service utilization, equity and mental health outcomes is also required to assess the impact of the new funding. Keeping track of changes in stigma will help to contextualize this information, because declining stigma could drive up demand and unmet need even as service availability is expanding. Both the Institute of Health Economics' comprehensive review of mental health spending from 2008 and the stigma module from the 2012 Canadian Community Mental Health Survey-Mental Health could be replicated now and repeated at five-year intervals. ${ }^{5,31}$ To ensure strong engagement from patients and families, this CIHR call could be led through the Strategy for Patient-Oriented Research..$^{32}$ Finally, ongoing research is always needed to improve the effectiveness (and cost-effectiveness) of programs, treatments and supports; for example, a recent cost-benefit analysis found that society would save $\$ 2$ for every $\$ 1$ invested in expanding Medicare coverage of psychological services. ${ }^{17}$ 


\section{Conclusion}

Generations of Canadians have been affected by gaps and inequities in mental health services. The new \$5-billion federal transfer is an important breakthrough, and a testament to political will and decades of advocacy, even if it will only go part of the way to closing gaps in funding. Without rigorous accountability mechanisms, and a willingness to learn quickly from Canadian experience and jurisdictions such as Australia and the UK, this opportunity could slip through our fingers. Stigma may be declining, but mental illness remains a substantial social problem, and fiscal and jurisdictional pressures in the Canadian context are as intense as ever. As a first step toward making the most of these new investments, governments should make the bilateral transfer agreements public.

\section{References}

1. Budget 2017: building a strong middle class. Ottawa: Finance Canada; 2017

2. Bartram M, Lurie S. Closing the mental health gap: The long and winding road? Can J Commun Ment Health 2017;36:1-14.

3. Changing directions, changing lives: the mental health strategy for Canada. Calgary: Mental Health Commission of Canada; 2012.

4. A 10-year plan to strengthen health care [First Ministers meeting 2003]. Ottawa: Health Canada; 2004. Available: www.scics.gc.ca/CMFiles/800042005_ e1JXB-342011-6611.pdf (accessed 2017 June 20).

5. Jacobs $P$, Dewa $C$, Lesage $A$, et al. The cost of mental health and substance abuse services in Canada. Edmonton: Institute of Health Economics; 2010.

6. Making mental health count. In: Focus on health. Paris: Organisation for Economic Co-operation and Development; 2014. Available: www.oecd.org/els/ health-systems/Focus-on-Health-Making-Mental-Health-Count.pdf (accessed 2017 June 20).

7. Sunderland A, Findlay LC. Perceived need for mental health care in Canada: results from the 2012 Canadian Community Health Survey-Mental Health. Health Rep 2013;24:3-9.

8. Canadian life and health insurance facts: 2016 edition. Toronto: Canadian Life and Health Insurance Association; 2016. Available: www.clhia.ca/domino/ html/clhia/CLHIA_LP4W_LND_Webstation.nsf/resources/Factbook_2/\$file/2016 + CLHIA+Factbook+ENG.pdf (accessed 2017 June 20).

9. Vasiliadis H-M, Tempier R, Lesage A, et al. General practice and mental health care: determinants of outpatient service use. Can J Psychiatry 2009;54:468-76.

10. Child and youth mental health in Canada [infographic]. Ottawa: Canadian Institute for Health Information; 2016. Available: www.cihi.ca/sites/default/ files/infographic_youthandmentalhealth2016-en.pdf (accessed 2017 June 20).

11. Guidelines for recovery-oriented practice. Ottawa: Mental Health Commission of Canada; 2015.

12 Sutherland G, Stonebridge C. Healthy brains at work: estimating the impact of workplace mental health benefits and programs. Ottawa: The Conference Board of Canada; 2016

13. Whiteford HA, Buckingham WJ, Harris MG, et al. Estimating treatment rates for mental disorders in Australia. Aust Health Rev 2014;38:80-5.

14. Meadows GN, Enticott JC, Inder B, et al. Better access to mental health care and the failure of the Medicare principle of universality. Med J Aust 2015;202: 190-4.

15. Community \& Mental Health team. Improving access to psychological therapies (IAPT): executive summary. Leeds (UK): NHS Digital; 2017. Available: http://content.digital.nhs.uk/catalogue/PUB24016 (accessed 2017 June 20).
16. Community \& Mental Health team. Psychological therapies: annual report on the use of IAPT services England, 2015-16. Leeds (UK): NHS Digital; 2016. Available: http://content.digital.nhs.uk/catalogue/PUB22110/psyc-ther-ann-rep -2015-16_v2.pdf (accessed 2017 June 20).

17. Vasiliadis H-M, Dezetter A, Latimer E, et al. Assessing the costs and benefits of insuring psychological services as part of Medicare for depression in Canada. Psychiatr Serv 2017;68:899-906.

18. 4326.0 - Mental health and well-being: profile of adults, Australia, 1997. Canberra: Australian Bureau of Statistics; 1998. Available: www.abs.gov.au/AUSSTATS/ abs@.nsf/allprimarymainfeatures/D5A0AC778746378FCA2574EA00122887? opendocument (accessed 2017 June 20).

19. Layard R, Clark D, Knapp M, et al. Cost-benefit analysis of psychological therapy. Natl Inst Econ Rev 2007;202:90-8.

20. Telehealth psychological services for people in rural areas. Canberra: Australian Government, Department of Health; 2017. Available: http://health.gov.au/internet /main/publishing.nsf/Content/mental-ba-telehealth (accessed 2017 Oct. 20).

21. The fifth national mental health and suicide prevention plan. Canberra: Australian Government, Department of Health; 2017. Available: http://coaghealthcouncil .gov.au/Portals/0/Fifth\%20National\%20Mental\%20Health\%20and\%20Suicide $\%$ 20Prevention\%20Plan.pdf (accessed 2017 Oct. 20).

22. National Commission of Audit (Australia); Shepherd AF. Towards responsible government: the report of the National Commission of Audit. Canberra: Australian Government, National Commission of Audit; 2014.

23. Curry B. Canadians were not impressed by federal budget: survey. Globe and Mail [Toronto]. 2017 Apr. 17. Available: https://www.theglobeandmail.com/news /politics/canadians-were-not-impressed-by-federal-budget-survey/article34720523/ (accessed 2017 June 20).

24. Butler A, Adair CE, Jones W, et al. Towards quality mental health services in Canada: a comparison of performance indicators across 5 provinces. Vancouver: Centre for Applied Research in Mental Health \& Addiction (CARMHA); 2017.

25. Major depression: care for adults and adolescents. In: Quality standards. Toronto: Health Quality Ontario; 2016.

26. Wilson M, Bradley L. Strengthening the case for investing in Canada's mental health system: economic considerations. Ottawa: Mental Health Commission of Canada; 2017. Available: https://www.mentalhealthcommission.ca/sites/ default/files/2017-03/case_for_investment_eng.pdf (accessed 2017 Sept. 14).

27. Marchildon $\mathrm{G}$. Bilateral health agreements between the federal and provincial/ territorial governments in Canada. IRPP Insight 2016;13:1-20.

28. Sousa C. 2017 Ontario budget: a stronger, healthier Ontario. Toronto: Ontario Ministry of Finance; 2017.

29. Health workforce database metadata. Ottawa: Canadian Institute for Health Information. Available: https://www.cihi.ca/en/health-workforce-database-metadata (accessed 2017 June 20).

30. Antipsychotic reduction collaborative: reducing antipsychotic medication use in long term care. Ottawa: Canadian Foundation for Healthcare Improvement. Available: www.cfhi-fcass.ca/WhatWeDo/reducing-antipsychotic-medication-use -collaborative (accessed 2017 June 20).

31. Stuart H, Patten SB, Koller M, et al. Stigma in Canada: results from a rapid response survey. Can J Psychiatry 2014;59(Suppl 1):S27-33.

32. Strategy for patient-oriented research. Ottawa: Canadian Institutes of Health Research; 2017. Available: www.cihr-irsc.gc.ca/e/41204.html (accessed 2017 June 20).

\section{Competing interests: None declared.}

This article was solicited and has been peer reviewed.

Affiliation: School of Public Policy and Administration, Carleton University, Ottawa, Ont.

Correspondence to: Mary Bartram, mary.bartram@carleton.ca 